\title{
Effects of Antenatal Colonization with Ureaplasma urealyticum on Pulmonary Disease in the Immature Baboon
}

\author{
BRADLEY A. YODER, JACQUELINE J. COALSON, VICKI T. WINTER, TERESA SILER-KHODR, \\ LYNNE B. DUFFY, AND GAIL H. CASSELL \\ Departments of Pathology [B.A.Y., J.J.C., V.T.W.] and Obstetrics-Gynecology [T.S.-K.], University of \\ Texas Health Science Center, San Antonio, Texas 78284; Pediatrix Medical Group [B.A.Y.], San Antonio, \\ Texas 78284; Department of Physiology and Medicine [B.A.Y.], Southwest Foundation for Biomedical \\ Research, San Antonio, Texas 78284; and Department of Microbiology [L.B.D., G.H.C.], University of \\ Alabama-Birmingham, Birmingham, Alabama 35249, U.S.A.
}

\begin{abstract}
Current nonhuman models for bronchopulmonary dysplasia have not included perinatal infection. We studied the effects of antenatal Ureaplasma urealyticum $(U u)$ infection in the $125-\mathrm{d}$ immature baboon. Ten 125-d gestation (term $=185 \mathrm{~d}$ ) baboon dams were delivered after intra-amniotic inoculation with $U u$. Serial blood and tracheal aspirate samples were analyzed for $U u$ colony-forming units, IL-6, IL-8, and cell counts. Physiologic parameters were serially recorded. Lung histology was examined after $14 \mathrm{~d}$ of ventilation and compared with unexposed controls. All $U u$-exposed animals had $>4 \times 10^{2} \mathrm{CFU}$ in tracheal aspirate at $24 \mathrm{~h}$. Four of nine $U u$ animals remained heavily colonized $[(+) U u]$ at necropsy $\left(>6 \times 10^{3}\right)$. Five animals had negative or low tracheal colony-forming units. All $U u$ animals had significant increases for white blood cells, IL-6, and IL-8 in amniotic and fetal lung fluid. Compared with controls, (+) $U u$ animals had significantly higher fraction of inspired oxygen, airway pressures, oxygenation index, and ventilation efficiency index between 48 and $240 \mathrm{~h}$ and had significantly elevated tracheal IL-6 and IL-8 concentrations between 72 and $240 \mathrm{~h}$. Compared with controls (-) $U u$ animals had significantly better oxygenation index and ventilation efficiency index scores between 48 and $144 \mathrm{~h}$. Lung histopathology in both $U u$ groups showed more severe bronchiolitis and interstitial pneumonitis compared with
\end{abstract}

\section{ABSTRACT}

controls. Two patterns of disease were observed after $U u$ perinatal infection. Persistent colonization manifested a picture consistent with acute pneumonitis, worse lung function from 2 to $10 \mathrm{~d}$, and prolonged elevated tracheal cytokines. Colonized animals that subsequently cleared $U u$ from the lung demonstrated early improved lung function compared with unexposed controls yet still manifested mixed bronchiolitis and interstitial pneumonitis at necropsy. Inherent immune system responses may determine outcome of perinatal Ureaplasma colonization. (Pediatr Res 54: 797-807, 2003)

$\quad$ Abbreviations
CFU, colony forming unit
Uu, Ureaplasma urealyticum
BPD, bronchopulmonary dysplasia
TA, tracheal aspirate
OI, oxygenation index
VEI, ventilatory efficiency index
Fio $_{2}$, fraction of inspired oxygen
Paco $_{2}$, arterial blood partial pressure carbon dioxide
Pao $_{2}$, arterial blood partial pressure oxygen
Paw, mean airway pressure $^{\text {a }}$

The pathogenesis of bronchopulmonary dysplasia (BPD) is incompletely understood, but pulmonary inflammation seems

Received January 31, 2003; accepted May 27, 2003.

Correspondence: Bradley A. Yoder, M.D., Room 321 E, Department of Pathology, UTHSCSA, 7703 Floyd Curl Drive, San Antonio, TX 78284; email: yoder@pathology.uthscsa.edu

Supported by National Institutes of Health Grants HL52636 and HL52646.

DOI: 10.1203/01.PDR.0000091284.84322.16 to play a critical key role (1-3). Pulmonary inflammation may be initiated by various insults, including hyperoxia, volutrauma, and infection. Recent reports suggest an important role for both postnatal and perinatal infection in the pathogenesis of BPD (4-7).

Evidence for microbial invasion of the amniotic cavity has been found in up to $80 \%$ of preterm births (8). The organism most commonly identified has been Ureaplasma urealyticum 
$(U u)(9-11)$. The presence of $U u$ in the preterm respiratory tract has been correlated with elevated cellular and molecular markers of inflammation and associated with an increased risk for BPD (7, 12-14).

Current nonhuman models for BPD are limited by the lack of perinatal infection as a confounding factor. A previous pilot study from this center demonstrated worse clinical and histologic hyaline membrane disease after $U u$ colonization of the 140-d preterm baboon (15). However, Ureaplasma colonization was conferred postnatally, and all animals were exposed to hyperoxia [fraction of inspired oxygen $\left(\mathrm{Fio}_{2}\right)$ 1.0]. Our current BPD model involves the more immature 125-d baboon, which manifests clinical and pathologic features similar to immature humans at risk for BPD today (16). These animals develop BPD in the presence of antenatal steroid therapy and prophylactic surfactant replacement therapy coupled with low-tidalvolume mechanical ventilation and appropriate oxygen support. The objective of this study was to characterize the clinical and pathologic response of the 125-d immature baboon to intrauterine amniotic fluid colonization with $U u$.

\section{METHODS}

Introduction of intra-amniotic Uu. All animal studies were performed at the Southwest Foundation for Biomedical Research in San Antonio, Texas. All animal husbandry, animal handling, and procedures were reviewed and approved by the Institutional Animal Care and Use Committee and conformed to American Association for Accreditation of Laboratory Animal Care guidelines. At 122-123 d timed gestation, 10 pregnant baboons (Papio papio) were anesthetized with ketamine hydrochloride $(10 \mathrm{mg} / \mathrm{kg}$, i.m. $)$ and restrained in a supine position. Under ultrasound guidance, an 18-gauge needle was inserted through aseptically prepared skin into the amniotic cavity and $10 \mathrm{~mL}$ of amniotic fluid was withdrawn. Five milliliters of fluid was allocated for microbial cultures (bacterial and Ureaplasma), cell count and differential, and cytokine assays as described below. The remaining $5 \mathrm{~mL}$ of sterile amniotic fluid was mixed with $5 \mathrm{~mL}$ of $U u$, serovar subtype 1, suspended in $10 \mathrm{~B}$ broth at a concentration of $10^{7}$ colonyforming units (CFU), and infused back into the amniotic cavity. Dams were recovered in normal manner and quarantined for 48-72 h before elective cesarean delivery under general anesthesia at $125 \pm 2 \mathrm{~d}($ term $=185 \mathrm{~d})$. All dams were treated postoperatively with azithromycin (Eli Lilly, Indianapolis, IN, U.S.A.) for $7 \mathrm{~d}$. Animals were not introduced back into the active colony until vaginal cultures and PCR were negative on two consecutive specimens. Neither Ureaplasmaexposed nor control animals received antenatal steroids before delivery. This was a pilot study to determine the feasibility and effects of antepartum Ureaplasma exposure in our immature animals model for BPD. The control animals also served as controls to more established projects within our BPD research program, which did not allow for sham intrauterine amniocentesis at the designated time.

Delivery and instrumentation. At birth, infants were weighed, sedated (ketamine $\mathrm{HCl}, 10 \mathrm{mg} / \mathrm{kg}$ ), and intubated with a $2.5-\mathrm{mm}$ endotracheal tube. Before the first breath, tracheal lung liquid was collected, then infants received a single bolus $(100 \mathrm{mg} / \mathrm{kg})$ of exogenous surfactant (Survanta, donated by Ross Laboratories, Columbus, OH, U.S.A.). Ventilation was initiated in all infants with a pressure-limited, time-cycled infant ventilator (InfantStar, donated by Infrasonics, San Diego, CA, U.S.A.) as previously described $(16,17)$. Animals were instrumented with an umbilical arterial catheter and percutaneous central venous catheter and nursed in a servocontrolled, infrared-warmed body plethysmograph (VT1000, VitalTrends Technology, New York, NY, U.S.A.). Intermittent sedation was provided as needed with ketamine (5 $\mathrm{mg} / \mathrm{kg})$ and $/$ or diazepam $(0.1 \mathrm{mg} / \mathrm{kg})$.

Ventilator management and pulmonary function testing. The ventilatory approach applied has been previously described $(16,17)$ Briefly, pressures were adjusted to maintain tidal volumes at $4-6 \mathrm{~mL} / \mathrm{kg}$ as measured by plethysmography and associated with adequate chest motion by clinical examination. Rate was adjusted to regulate arterial blood partial pressure carbon dioxide $\left(\mathrm{PaCO}_{2}\right)$ between 45 and 55 torr. Target goals for $\mathrm{PaO}_{2}$ were 55-70 torr. Oxygenation was primarily manipulated through changes in positive end expiratory pressure and $\mathrm{Fio}_{2}$. Oxygenation index [OI; $\mathrm{Fio}_{2} * 100 *$ mean airway pressure $(\mathrm{Paw}) /$ arterial blood partial pressure oxygen $\left.\left(\mathrm{PaO}_{2}\right)\right]$ and ventilation efficiency index (VEI; $\mathrm{PaCO}_{2} *$ rate $*$ peak inspiratory pressure/1000) were used as indices for oxygenation and ventilation. Pulmonary function testing was performed using the VT1000 body plethysmograph as previously reported $(16,17)$. Briefly, 10 breaths, meeting predefined breath selection criteria, were recorded at each time point and averaged for determination of tidal volume $(\mathrm{mL} / \mathrm{kg})$, dynamic respiratory system compliance $\left(\mathrm{mL} \cdot \mathrm{cm} \mathrm{H}_{2} \mathrm{O}^{-1} \cdot \mathrm{kg}^{-1}\right)$, and expiratory resistance $\left(\mathrm{cm} \mathrm{H}_{2} \mathrm{O} \cdot \mathrm{L}^{-1} \cdot \mathrm{s}^{-1}\right)$. Variability between measurements was compared by periodic triplicate recording of pulmonary function tests and was consistently $<10 \%$.

Other care plans. Animals were not enterally fed during this 14-d study. Parenteral nutrition was initiated at $24 \mathrm{~h}$ of life (16, 17). Arterial blood gases, hematocrit, and serum chemistries were measured at designated time intervals. Hematocrit was maintained between 30 and $45 \%$ through periodic administration of fresh, heparinized packed red cells obtained from adult baboons. All animals were treated with antibiotics (ampicillin and amikacin) for the duration of the study. Prophylactic fluconazole was initiated in all animals with $6.0 \mathrm{mg} \cdot \mathrm{kg}^{-1}$. $\operatorname{dose}^{-1}$ at $12 \mathrm{~h}$ of age and repeated at 96,168 , and $240 \mathrm{~h}$ of age.

Microbiology. The following specimens were processed for culture and PCR for $U u$ : amniotic fluid, fetal lung liquid, endotracheal aspirate, fetal membrane, decidua, periodic blood samples, lung, and brain. Specimens were transported in 10B media for culture and PCR transport buffer. Amniotic fluid was concentrated before inoculating the transport media. Fluid was centrifuged for $10 \mathrm{~min}$ at $10,000 \mathrm{rpm}$, and the supernatant was removed. The pellet was resuspended in $1 \mathrm{~mL}$ of residual fluid, and $300 \mu \mathrm{L}$ was added to the transport media. Samples (150 $\mu \mathrm{L}$ ) of fetal lung liquid and endotracheal aspirates, collected as described below, were added to each of the transport media. Fetal membrane cultures were collected by swabbing between the chorion and the amnion with three Dacron swabs. Swab 1 was inoculated into culture media, swab 2 was inoculated into 
PCR buffer, and swab 3 was inoculated into sucrose phosphate buffer for storage. Swabs were rinsed in the respective vials and swirled, excess fluid was removed by pressing the swab against the inside of the vial, and the swab was discarded. At necropsy, all tissue samples were finely minced with scissors and sterile blades in $2 \mathrm{~mL}$ of sterile sucrose phosphate buffer. A $300 \mu \mathrm{L}$ sample of each tissue specimen was added to a culture transport and a PCR buffer. Specimens were frozen immediately upon collection at $-70^{\circ} \mathrm{C}$ until transported on dry ice to the Diagnostic Mycoplasma Laboratory at the University of Alabama Birmingham. Once received at the Diagnostic Mycoplasma Laboratory, culture specimens were thawed and processed by quantitative culture using $10 \mathrm{~B}$ broth and $\mathrm{A} 8$ agar for $U u$. Previously published protocols were used (18). PCR for $U u$ was performed on batched specimens using standard techniques. The primers for $U u$ were directed toward the urease gene (19).

Pathology: light microscopy. At necropsy, the right lower lobe was removed, weighed, and intrabronchially fixed with phosphate-buffered $4 \%$ paraformaldehyde and $0.1 \%$ glutaraldehyde at $20 \mathrm{~cm} \mathrm{H}_{2} \mathrm{O}$ constant pressure for $24 \mathrm{~h}$. After fixation, the volume of the right lower lobe was determined by volume displacement. The lobe was cut into three serial, equally spaced horizontal tissue sections. The entire cut surfaces of all three horizontal sections were processed for light microscopic study. These specimens were dehydrated in alcohol, embedded in paraffin, cut at $4 \mu \mathrm{m}$, and stained with hematoxylin and eosin. Airway inflammation and interstitial pneumonitis was subjectively assessed and graded as absent, mild, and moderatesevere, and the number of intra-alveolar macrophages were judged to be minimal or numerous in quantity.

Tracheal aspirates. Tracheal aspirates (TA) were collected at approximately $24,72,120,240$, and $336 \mathrm{~h}$ as previously described $(16,17)$. Each aspirate was separated for cell count and differential specimens (transferred by Nunc tube on wet ice to the laboratory); cytokine samples were centrifuged for 10 min at $2500 \mathrm{rpm}$, and the supernatant was removed and allocated in $0.25-\mathrm{mL}$ aliquots, then frozen at $-70^{\circ} \mathrm{C}$ until assay. IL-6 was measured using a specific antiserum to human IL-6 (Sigma Chemical Co., St. Louis, MO, U.S.A.) at a final dilution of 1:100,000, with radiolabeled human IL-6 from New England Nuclear and purified human IL-6 for the standard (Austral Biologicals, San Ramon, CA, U.S.A.). Assay sensitivity was $0.6 \mathrm{pg} /$ tube, and the intra- and interassay coefficients of variation were $6.5 \%$ and $11.9 \%$, respectively. An enzyme immunoassay (Applied Biosystems, Foster City, CA, U.S.A.) was used to measure IL-8. Assay sensitivity was $100 \mathrm{pg} / \mathrm{mL}$, and the intra-and interassay coefficients of variation were $10 \%$ and $24 \%$.

Data analyses. Data are presented as mean \pm SEM or median with interquartile ranges. Between-group differences for continuous data were compared by unpaired $t$ tests, MannWhitney $U$ test, ANOVA, or Kruskal-Wallis tests as indicated. Ordinal data were compared by Mann-Whitney $U$ or KruskalWallis tests. Categorical data were compared by Fisher's exact test or $\chi^{2}$. Comparisons among various time points were made using one-way ANOVA for repeated measures. $P<0.05$ was required for significance. Statistical results were generated using SPSS, version 9.0 (SPSS, Chicago, IL, U.S.A.).

\section{RESULTS}

None of the dams was culture or PCR positive for $U u$ in the amniotic fluid before inoculation, but all had positive amniotic fluid cultures at delivery (range $3.60 \times 10^{4}$ to $2.05 \times 10^{7}$ ). This range of CFUs is consistent with those found in a group of human women delivered by cesarean section at $<34$ wk gestation with histologic chorioamnionitis (Cassell G, Duffy L, unpublished data). None of the dams manifested signs of localized or systemic infection during the interval from inoculation to delivery, and there was no evidence for premature labor. Among dams inoculated with $U u$, there was a marked rise in amniotic fluid levels for white blood cells, IL-6, and IL-8 at the time of delivery (Table 1), but there was no effect on maternal or neonatal serum levels for these variables. All placental tissues except one were inadvertently sent only for culture studies. In the single placenta available for microscopic examination after intrauterine $U u$ exposure, there was histologic evidence of acute inflammation of the chorioamniotic membranes, a finding not seen in any control placentas examined to date.

All fetuses exposed to intra-amniotic $U u$ were born alive. One infant died at $28 \mathrm{~h}$ of age as a result of severe cardiovascular compromise (data not included); all others survived until necropsy at $14 \mathrm{~d}$ of age. There were no differences between control infants and $U u$-exposed infants for gestational age (125 \pm 1 versus $125 \pm 1 \mathrm{~d})$, birth weight $(408 \pm 49$ versus $391 \pm$ $28 \mathrm{~g}$ ), or sex (63\% male versus $60 \%$ male). As shown in Table 2 , serial TA cultures revealed a dichotomous pattern for $U u$ exposed infants. Two discrete groups of infants were identified on the basis of the presence of high $(+U u ; n=4)$ versus low/no $(-U u ; n=5) U u$ CFUs at necropsy. The median

Table 1. Effect of intra-amniotic Uu colonization on amniotic fluid cytokine and white blood cell concentrations of baboon dams

\begin{tabular}{lccc}
\hline & Preinoculation $(n=10)$ & Delivery $(n=10)$ & $p$ \\
\hline IL-6* & $1840(1409-2417)$ & $3242(2741-5582)$ & 0.016 \\
IL-8* & $311(215-619)$ & $10214(4617-43,690)$ & $<0.001$ \\
Total white blood count $\dagger$ & $428(16-844)$ & $15000(3500-110,249)$ & 0.018 \\
Neutrophil count $\dagger$ & $32(0-580)$ & $13125(1407-100,688)$ & 0.033 \\
Macrophage/monocyte count $\dagger$ & $0(0-560)$ & $1500(437-7500)$ & 0.029 \\
\hline
\end{tabular}

All values as median $(25 \%-75 \%)$

$* \mathrm{pcg} / \mathrm{mL}$.

$\dagger$ Cells $/ \mathrm{mL}$. 
Table 2. CFUs for Uu in amniotic fluid and TA of 125-day premature baboons

\begin{tabular}{|c|c|c|c|c|c|c|c|}
\hline $\begin{array}{c}\text { Animal } \\
\text { no. }\end{array}$ & $\begin{array}{c}\mathrm{AF} \\
\text { pre- } U u\end{array}$ & $\begin{array}{c}\text { Incubation } \\
\text { hours }\end{array}$ & $\begin{array}{c}\text { AF } \\
\text { delivery }\end{array}$ & TA $24 \mathrm{~h}$ & TA $72 \mathrm{~h}$ & TA $144 \mathrm{~h}$ & $\begin{array}{c}\text { TA, } \\
\text { necropsy }\end{array}$ \\
\hline $3 F$ & 0 & 48 & $4.4 \times 10^{5}$ & $7.5 \times 10^{3}$ & $6.0 \times 10^{5}$ & $2.1 \times 10^{5}$ & $6.2 \times 10^{3}$ \\
\hline $3 Q$ & 0 & 48 & $1.0 \times 10^{6}$ & $9.0 \times 10^{3}$ & $1.2 \times 10^{5}$ & $2.0 \times 10^{2}$ & $4.5 \times 10^{4}$ \\
\hline $4 \mathrm{D}$ & 0 & 72 & $2.1 \times 10^{6}$ & $1.5 \times 10^{3}$ & $3.7 \times 10^{5}$ & $1.3 \times 10^{7}$ & $1.6 \times 10^{3}$ \\
\hline $2 \mathrm{~F}$ & 0 & 72 & $9.5 \times 10^{5}$ & $1.1 \times 10^{5}$ & $2.1 \times 10^{6}$ & $4.1 \times 10^{6}$ & $2.2 \times 10^{5}$ \\
\hline $3 \mathrm{G}$ & 0 & 48 & $2.4 \times 10^{5}$ & $4.5 \times 10^{2}$ & 50 & 1 & 150 \\
\hline $3 Y$ & 0 & 72 & $1.2 \times 10^{7}$ & $2.9 \times 10^{3}$ & $3.0 \times 10^{3}$ & 0 & 0 \\
\hline $3 X$ & 0 & 48 & $5.2 \times 10^{6}$ & $3.7 \times 10^{4}$ & $3.7 \times 10^{6}$ & $1.0 \times 10^{2}$ & 0 \\
\hline $1 \mathrm{Y}$ & 0 & 72 & $6.4 \times 10^{4}$ & $2.5 \times 10^{5}$ & $5.6 \times 10^{4}$ & $7.9 \times 10^{3}$ & 0 \\
\hline $2 \mathrm{~S}$ & 0 & 72 & $2.0 \times 10^{7}$ & $1.0 \times 10^{2}$ & 1 & 0 & 0 \\
\hline
\end{tabular}

AF, amniotic fluid.

values for $U u$ CFUs from TAs were significantly different $(p<$ 0.05 , Mann-Whitney $U$ ) between these two groups by day 6 of life until necropsy.

Comparison between all $U u$-exposed infants and controls revealed no differences in clinical, physiologic, or ventilatory variables at any designated interval from birth until necropsy (data not shown). However, comparisons between control infants and the $U u$ subgroups, (+) $U u$ and (-) $U u$ revealed important differences in lung function and histopathology.

Oxygenation was similar in all three groups until $48 \mathrm{~h}$ of age. From $48 \mathrm{~h}$ of age until $240 \mathrm{~h} \mathrm{(+)} U u$ infants required higher $\mathrm{FiO}_{2}$ support at multiple time points compared with control and (-) Uu infants to achieve target $\mathrm{PaO}_{2}$ (Fig. 1A) The need for higher $\mathrm{FiO}_{2}$ among (+) $U u$ infants was accompanied by higher mean airway pressure (Fig. $1 B$ ). The end result of increased $\mathrm{Fio}_{2}$ and mean airway pressure requirements in $(+)$ $U u$ animals was a significant increase in OI from $48 \mathrm{~h}$ until $240 \mathrm{~h}$ as shown in Figure 1C. It is interesting that by necropsy at day 14 , there were no differences in oxygenation parameters between $(+) U u$ animals and controls. There were divergent patterns for $\mathrm{FiO}_{2}$, mean airway pressure, and OI between $(+)$ $U u$ and $(-) U u$ animals. Whereas $(+) U u$ animals manifested worse oxygenation compared with controls, (-) $U u$ animals trended toward improved oxygenation compared with controls, with differences being significant at 5, 6, and $14 \mathrm{~d}$ (Fig. 1).

Measures of ventilation followed a course similar to oxygenation. There were no differences between groups until after $48 \mathrm{~h}$ of age. From $72 \mathrm{~h}$ age through $240 \mathrm{~h}$ age, the (+) $U u$ animals required increased peak inspiratory pressures (Fig. $2 A$ ) and increased ventilator rates (Fig. $2 B$ ) compared with control and (-) $U u$ animals. The VEI, a measure of the amount of ventilator support required to achieve a specific level of ventilation, is shown in Figure $2 C$. The VEI was significantly elevated from 48 through $240 \mathrm{~h}$ in (+) $U u$ animals compared with controls and (-) $U u$ animals and remained elevated at $336 \mathrm{~h}$ compared with (-) $U u$ animals. As with oxygenation, there were no significant differences for ventilation indices between controls and (+) Uu animals at the time of necropsy, and ventilation was more easily achieved in (-) $U u$ animals than in controls with significant differences found on days 5,6 , and 14 (Fig. 2).

Pulmonary function testing did not tend to mirror group differences found for oxygenation and ventilation parameters (Fig. 3). Initial (6 h of age) airway resistance was significantly higher among $(+) U u$ animals compared with controls and $(-)$
$U u$ infants, but there was wide variability within and overlap between groups at the various time points compared (Fig. 3A). There was a consistent and significant decrease over time in airway resistance within each of the three study groups $(p<$ 0.05 by repeated measures ANOVA). Dynamic respiratory compliance did not differ between groups over the initial several days of life (Fig. $3 B$ ). By day 10, there was a significantly lower compliance among (+) $U u$ animals compared with controls and (-) $U u$ animals, but at necropsy on day 14, this was reversed and control animals had a lower respiratory dynamic compliance than either of the $U u$ groups. Wide variability existed within groups, but over the 14-d study period, there was a significant improvement in compliance within each group ( $p<0.05$, repeated measures ANOVA).

We measured cytokine levels (IL-6 and IL-8 in blood and TAs) and white blood cell counts in TAs as indicators of systemic and pulmonary inflammation. There were no between-group differences at specified time points from birth to necropsy for concentrations of IL-6 or IL-8 in the serum (data not shown). There also were no differences within groups over time (repeated measures ANOVA) for serum cytokine levels. In contrast, IL-6 levels were dramatically higher in both $U u$ groups compared with controls in fetal lung liquid and 24-h TAs (Table 3). Although TA IL-6 concentrations decreased over time in all animals, they remained significantly higher in the (+) $U u$ animals compared with controls and (-) Uu animals from $72 \mathrm{~h}$ through $240 \mathrm{~h}$. TA concentrations for IL-8 manifested a different pattern than IL-6 (Table 3). Among (-) $U u$ animals, IL-8 concentrations peaked at $24 \mathrm{~h}$ (significantly higher than controls) and then decreased to levels similar to controls for the remainder of the 14-d study period. IL-8 values increased from birth through $72 \mathrm{~h}$ for $(+) U u$ animals, then slowly decreased over time but remained significantly greater than control and (-) $U u$ animals until $240 \mathrm{~h}$ age. Although total white blood cells and percentage of neutrophils in TAs trended toward higher values in the (+) $U u$ animals, the only time point that was significantly different occurred at $72 \mathrm{~h}$.

Histopathologic findings are shown in Table 4. Bronchiolitis, interstitial pneumonitis, and alveolar macrophage accumulations, when present, were focal in distribution in all animals. This focal involvement is important to note, because most of these lesions were microscopic, not macroscopic, and would likely not be discernible radiographically. Bronchiolitis was less commonly seen in the control group when compared with the $U u$ study animals (Figs. 4 and $5 A$ ). Interstitial pneumonitis 


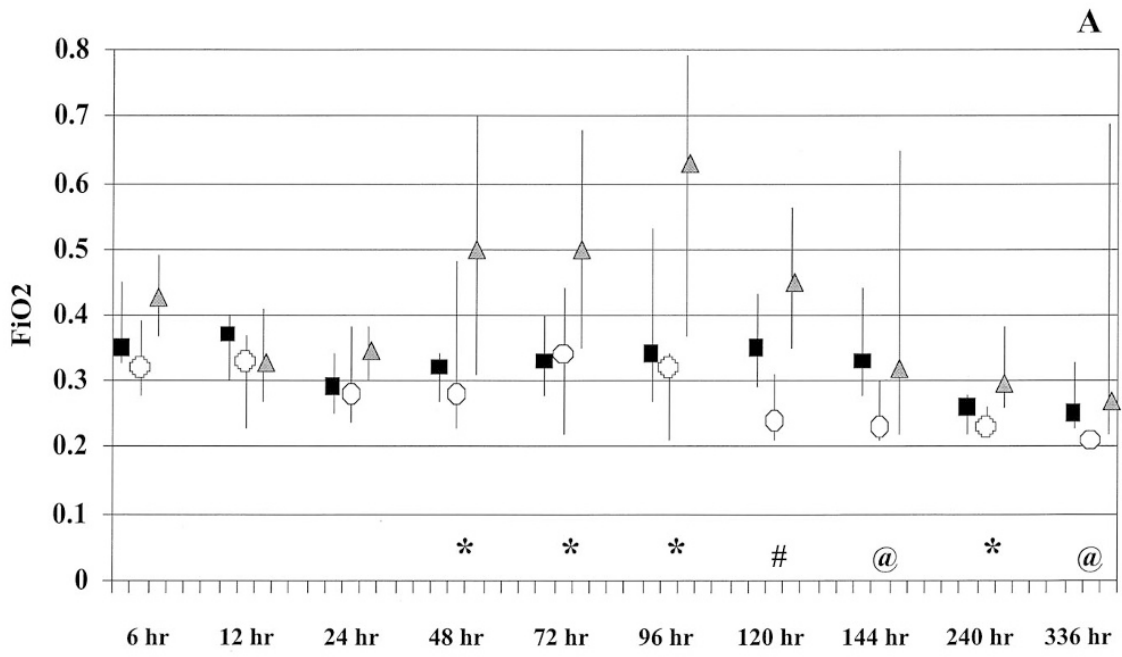

Hour of Life

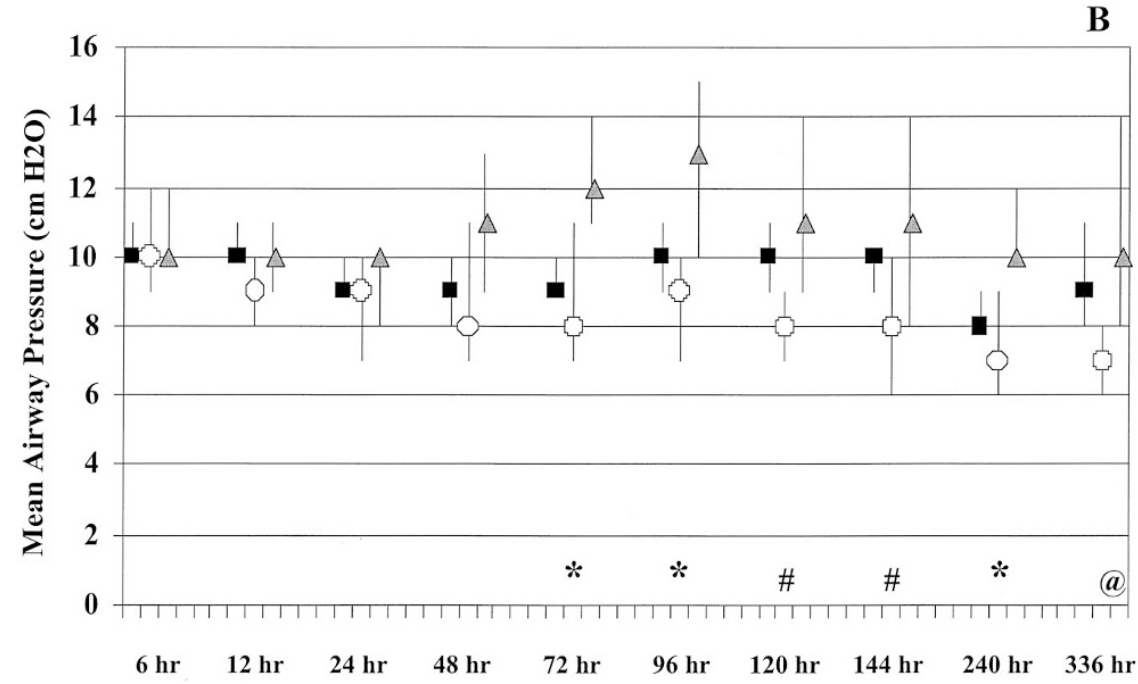

Hour of Life

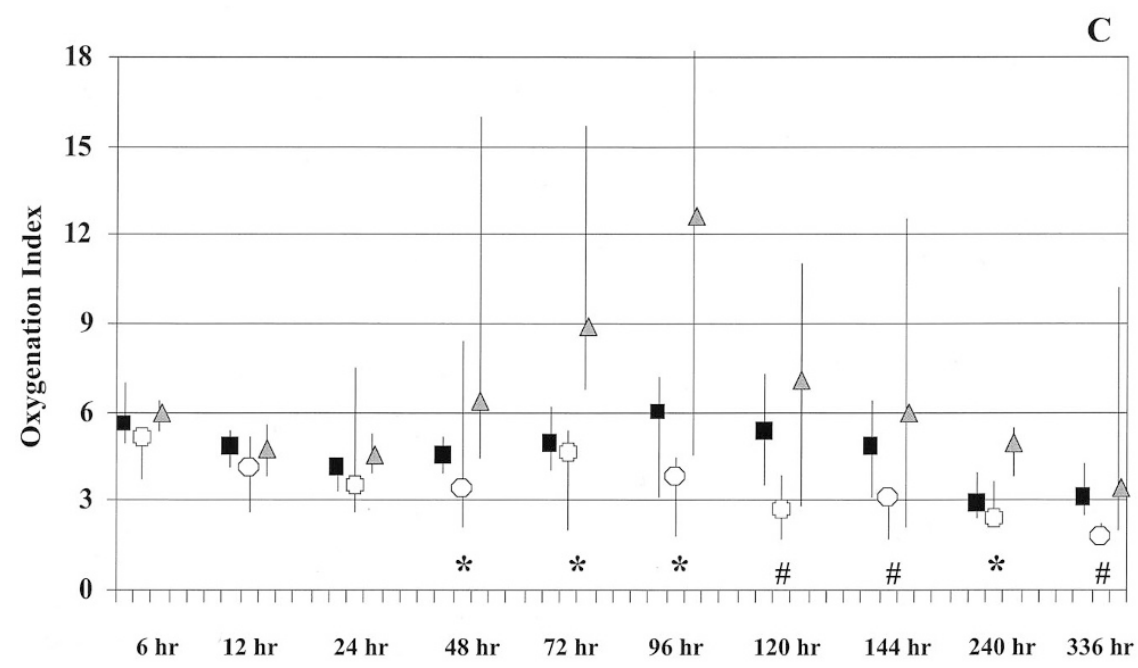

Hour of Life

Figure 1. Effect of intra-amniotic $U u$ exposure on postnatal oxygenation in 125-d premature baboons. Data are expressed as median and quartiles. $\mathbf{\square}$, unexposed controls; $\triangle$, exposed infants that had persistently positive tracheal cultures $[(+) U u] ; \bigcirc$, exposed infants that subsequently cleared $U u$ from the trachea $[(-) U u]$. (A) $\mathrm{FiO}_{2}$. (B) Mean airway pressure (Paw). (C) OI $\left(\mathrm{FiO}_{2} * 100 * \mathrm{Paw} / \mathrm{PaO}_{2}\right) .{ }^{*} p<0.05$ for $(+) U u$ vs control and $(-) U u$; $\# p<0.05$ for each group $v s$ the others; @ $p<0.05$ for $(-) U u$ vs control and $(+) U u$. ANOVA with Student-Newman-Keuls post hoc analysis. 
A

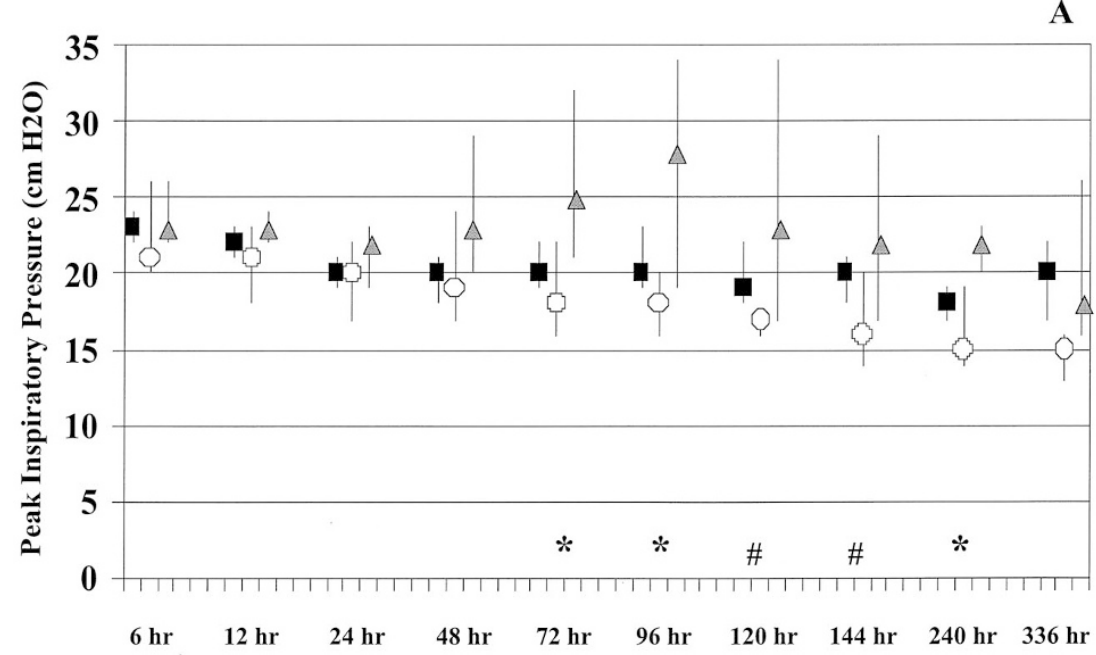

Hour of Life

B

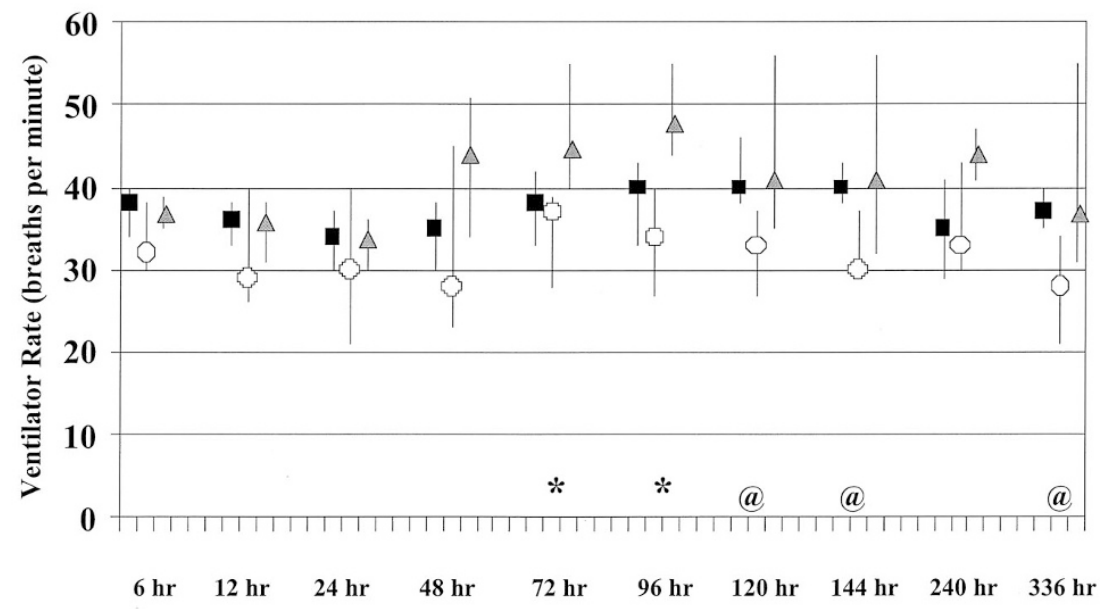

Hour of Life

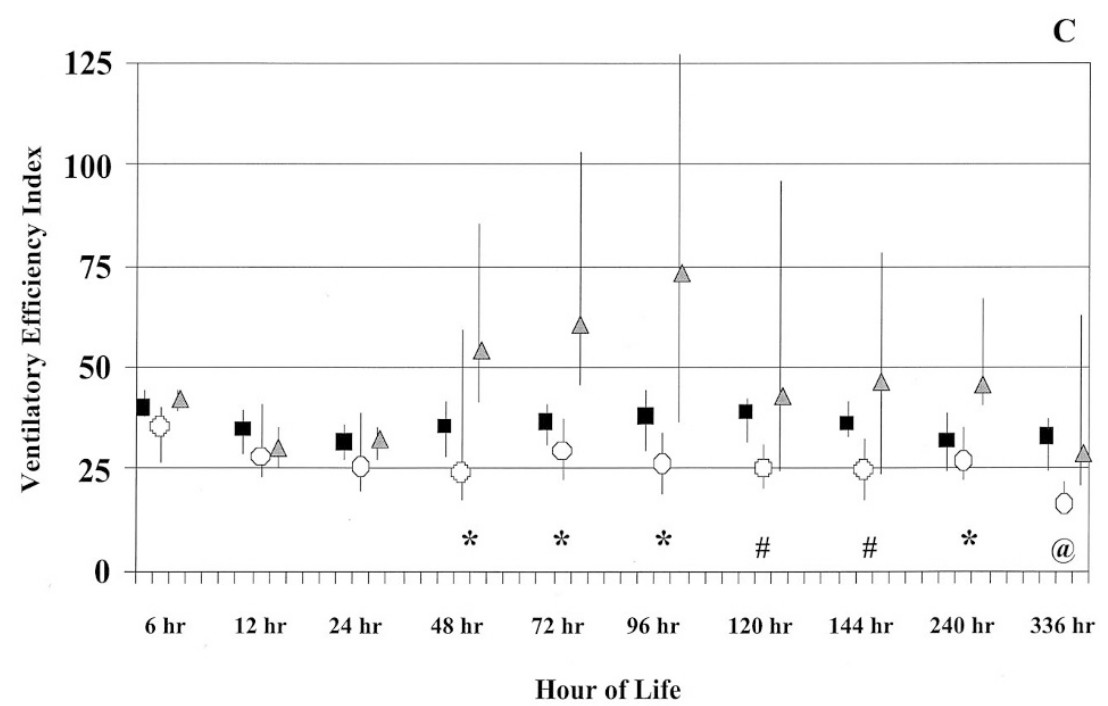

Figure 2. Effect of intra-amniotic $U u$ exposure on postnatal ventilation in 125-d premature baboons. Data are expressed as median and quartiles. $\boldsymbol{\square}$, unexposed controls; $\triangle$, exposed infants that had persistently positive tracheal cultures $[(+) U u] ; \bigcirc$, exposed infants that subsequently cleared $U u$ from the trachea $[(-) U u]$. (A) Peak inspiratory pressure (PIP). (B) Ventilator rate. (C) VEI $\left(\mathrm{PaCO}_{2} *\right.$ rate * PIP/1000). ${ }^{*} p<0.05$ for $(+) U u v s$ control and $(-) U u$; $\# p<0.05$ for each group vs the others; @p $<0.05$ for (-) Uu vs control and (+) Uu. ANOVA with Student-Newman-Keuls post hoc analysis. 


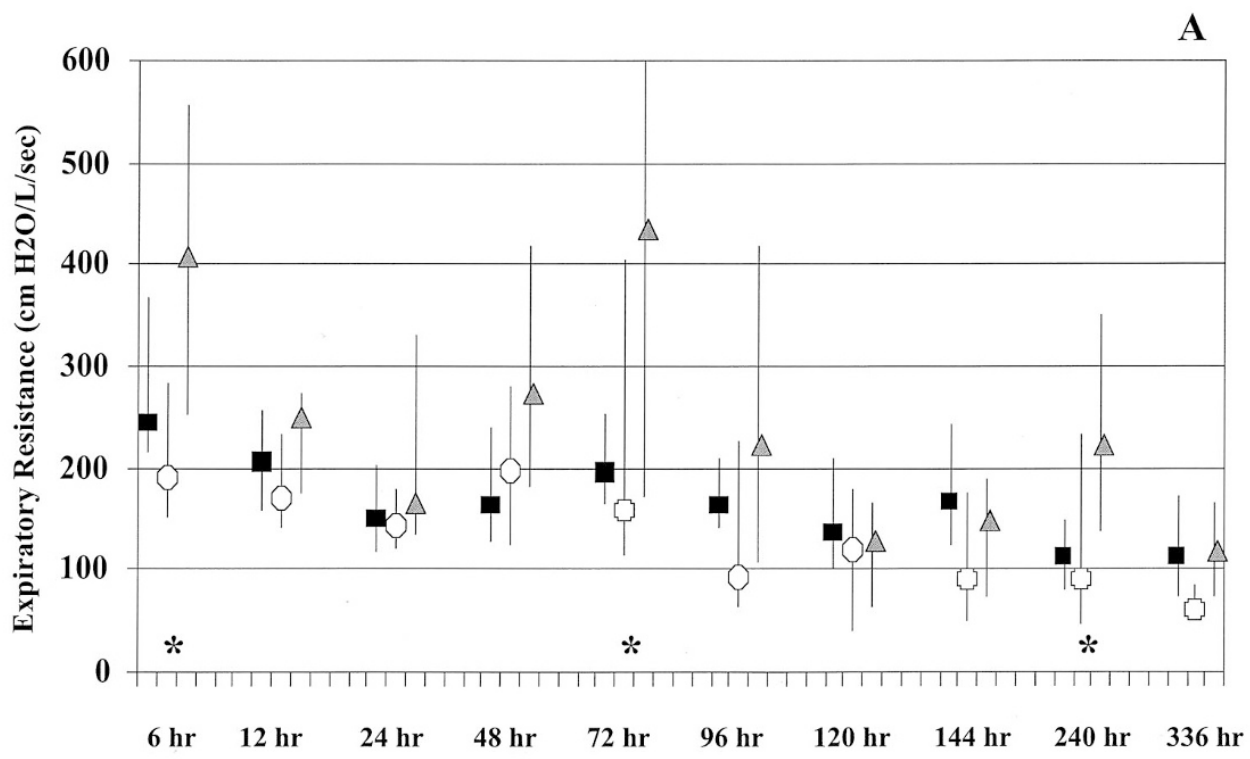

Hour of life

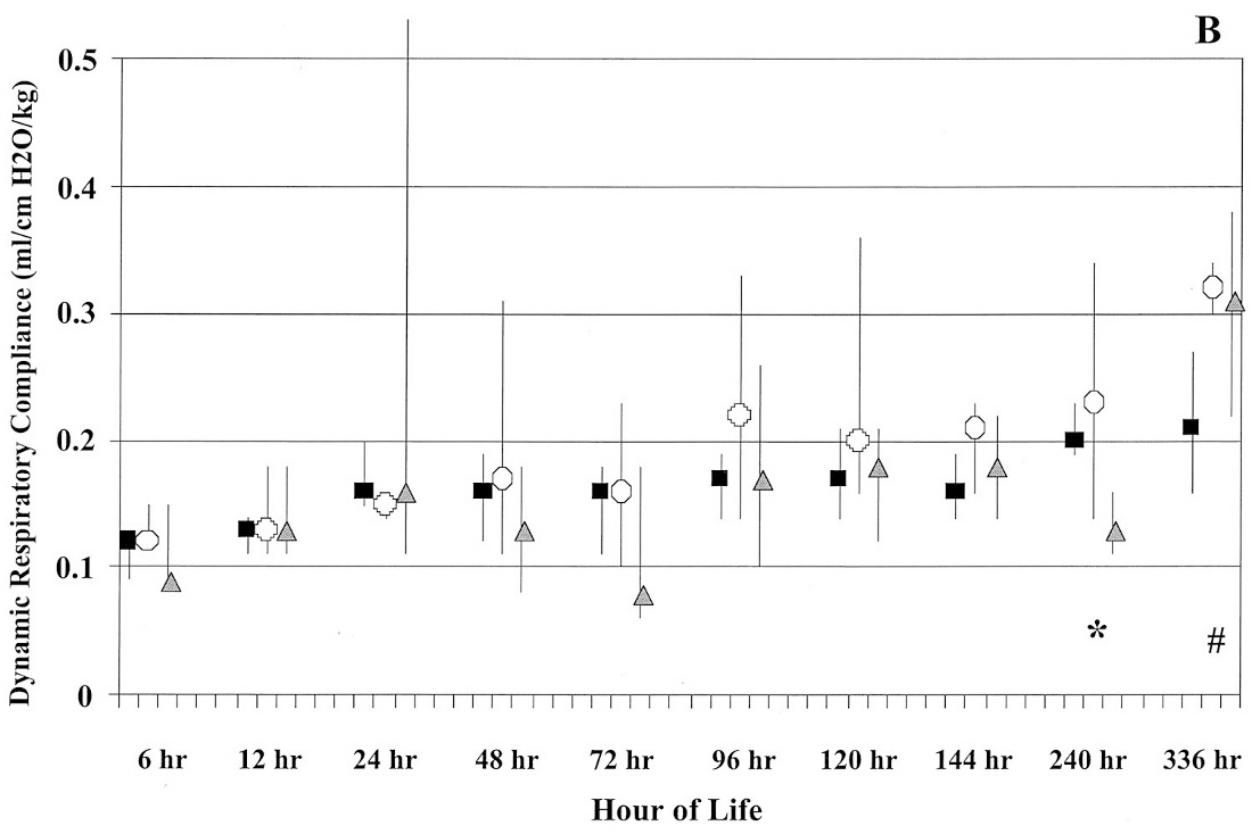

Figure 3. Effect of intra-amniotic $U u$ exposure on pulmonary function tests in 125-d premature baboons. $(A)$ Expiratory resistance. $(B)$ Dynamic respiratory compliance. Data are expressed as median and quartiles. $\mathbf{\square}$, unexposed controls; $\triangle$, exposed infants that had persistently positive tracheal cultures $[(+) U u]$; $\bigcirc$, exposed infants that subsequently cleared $U u$ from the trachea $[(-) U u] .{ }^{*} p<0.05$ for $(+) U u v s$ control and $(-) U u$; $\# p<0.05$ for each group $v s$ the others. ANOVA with Student-Newman-Keuls post hoc analysis.

greater than a mild designation was not found in the control group, whereas several of the $U u$ specimens had moderate to severe microscopic grades (Fig. 4). Control animals showed scattered alveolar macrophages in alveolar/saccular spaces subjacent to bronchioles, whereas the $U u$ groups typically had more numerous alveolar macrophages (Figs. 4 and $5 B$ ). The most severely affected animal $[2 \mathrm{~F},(+) U u]$ had more numerous polymorphonuclear neutrophils intermixed with the chronic inflammatory exudate and had the highest TA $U u$ CFU count at necropsy $\left(2.2 \times 10^{5}\right.$; Fig. $\left.5 B\right)$.

\section{DISCUSSION}

After $48-72 \mathrm{~h}$ of exposure to intra-amniotic $U u$, we found significant early elevations in tracheal cytokines and white blood cells among all exposed infants compared with unexposed controls. Although early lung function and mechanics were similar between $U u$-exposed infants and controls, by $48 \mathrm{~h}$ of age, two distinct patterns emerged among $U u$-exposed infants. One group, designated (+) $U u$, manifested persistent cytokine (IL-6 and IL-8) elevation in TAs accompanied by 
Table 3. IL concentrations from TAs of unexposed controls compared with antenatal Uu-exposed infants by presence of Uu in TAs at necropsy in 125-d premature baboons

\begin{tabular}{cccc}
\hline & Control & $(-) U u$ & $(+) U u$ \\
\hline IL-6 $(\mathrm{pcg} / \mathrm{mL})$ & $(n=5)$ & $(n=5)$ & $(n=4)$ \\
Fetal lung fluid & $1181(930-1365)^{*}$ & $3613(2430-15,193)$ & $5171(2535-22,972)$ \\
$24 \mathrm{~h}$ & $583(321-706)^{*}$ & $996(1467-2498)$ & $2214(211-2385)$ \\
$72 \mathrm{~h}$ & $666(348-852)$ & $435(183-850)$ & $1356(1167-2064) \dagger$ \\
$120 \mathrm{~h}$ & $791(189-807)$ & $491(134-989)$ & $1107(857-2075) \dagger$ \\
$240 \mathrm{~h}$ & $300(196-463)$ & $199(60-1487)$ & $1043(775-1350) \dagger$ \\
$336 \mathrm{~h}$ & $424(186-785)$ & $(n=5)$ & $(n=4)$ \\
IL-8 $\mathrm{pcg} / \mathrm{mL})$ & $(n=8)$ & $13,049(6507-67,568)$ & $1285)$ \\
Fetal lung fluid & Not available & $26,179(11,080-84,206)$ & $33,603(3910-33,254)$ \\
$24 \mathrm{~h}$ & $2527(169-6255)^{*}$ & $10,207(4182-28,832)$ & $50,357(7200-127,685)$ \\
$72 \mathrm{~h}$ & $8134(283-17,415)$ & $8801(2938-331,682)$ & $30,218(11,065-62,778)$ \\
$120 \mathrm{~h}$ & $6357(2435-20,098)$ & $4264(249-24,958)$ & $27,050(6360-79,907) \dagger$ \\
$240 \mathrm{~h}$ & $3962(794-14,913)$ & $1336(1053-10,917)$ & $11,006(6974-12,713)$ \\
$336 \mathrm{~h}$ & $18,176(1968-50,720)$ & & \\
\hline
\end{tabular}

Values as median (range).

${ }^{*} p<0.05$ by post hoc analysis $v s(-) U u$ and (+) Uu.

$\dagger p<0.05$ by post hoc analysis $v s$ control and (-) Uu.

Table 4. Graded lung histopathology for unexposed controls compared with antenatal $U u$, exposed infants by presence of Uu in TAs at necropsy in 125-d premature baboons

\begin{tabular}{|c|c|c|c|}
\hline & Bronchiolitis* & Pneumonitis & Macrophages* \\
\hline \multicolumn{4}{|c|}{ Controls } \\
\hline 3B & 0 & 0 & 1 \\
\hline $3 \mathrm{C}$ & 0 & 1 & 1 \\
\hline $2 \mathrm{~W}$ & 0 & 1 & 1 \\
\hline $1 \mathrm{R}$ & 0 & 1 & 2 \\
\hline $1 \mathrm{~F}$ & 0 & 0 & 1 \\
\hline $3 \mathrm{~T}$ & 1 & 1 & 1 \\
\hline $4 \mathrm{C}$ & 0 & 1 & 1 \\
\hline $3 \mathrm{H}$ & 0 & 1 & 1 \\
\hline $4 \mathrm{~W}$ & 0 & 1 & 1 \\
\hline $4 \mathrm{~N}$ & 0 & 1 & 1 \\
\hline $4 \mathrm{~T}$ & 0 & 1 & 1 \\
\hline $5 \mathrm{G}$ & 0 & 0 & 1 \\
\hline $4 X$ & 0 & 0 & 1 \\
\hline \multicolumn{4}{|c|}{$(-) U u$} \\
\hline $3 \mathrm{G}$ & 1 & 1 & 1 \\
\hline $3 X$ & 0 & 0 & 1 \\
\hline $3 Y$ & 1 & 2 & 2 \\
\hline $1 \mathrm{Y}$ & 2 & 0 & 2 \\
\hline $2 \mathrm{~S}$ & 2 & 1 & 2 \\
\hline \multicolumn{4}{|c|}{ (+) $U u$} \\
\hline $3 \mathrm{~F}$ & 0 & 1 & 1 \\
\hline $3 Q$ & 1 & 1 & 1 \\
\hline $4 \mathrm{D}$ & 2 & 2 & 2 \\
\hline $2 \mathrm{~F}$ & 2 & 3 & 3 \\
\hline
\end{tabular}

$* p<0.02$ by Mann-Whitney $U$ for controls vs $U u$. Bronchiolitis and pneumonitis grades: 0 , absent; 1 , mild, with $1-2$ cell layer of mononuclear cells, rare neutrophils; 2 , moderate, with $>2$ cell layer of mononuclear cells, rare neutrophils; 3 , severe, with $>2$ cell layer of mononuclear cells, more numerous neutrophils, intermixed intra-alveolar macrophages and scattered neutrophils. Alveolar macrophage grades: 1 , minimal, $<10$ per alveolar space; 2 , numerous, $>10$ in confluent group of alveoli.

significantly worse lung function than control infants. The clinical and radiographic features of these animals were consistent with an acute pneumonitis. Infants with the second pattern, designated (-) Uu, showed a reduction in tracheal cytokines and white blood cells after $48 \mathrm{~h}$ of age associated with significantly improved lung function compared with control infants. The unique contrast between these two groups of antenatal $U u$-exposed infants was persistent tracheal colonization in the (+) $U u$ animals out to necropsy at $14 \mathrm{~d}$. After $14 \mathrm{~d}$ of mechanical ventilation, (-) Uu infants demonstrated improved oxygenation and ventilation compared with controls and (+) $U u$ animals, but there were no differences in pulmonary mechanics or tracheal markers of inflammation between unexposed controls or either group of $U u$-exposed infants. Histopathologic examination revealed focal airway and saccular inflammation in several of the $U u$-exposed infants compared with controls. Our study suggests a role for $U u$ in the development of chronic lung injury of some immature infants, but the critical finding is the differential response to $U u$ among an apparently homogeneous group of antenatally exposed, immature, nonhuman primate infants.

Cassell et al. (12) first suggested an association between BPD and colonization of the premature infant's lower respiratory tract by $U u$ in 1988 . Several subsequent studies also found this association, with a noted predisposition among premature infants $<1500 \mathrm{~g}(13,20-27)$. Other reports have not confirmed this correlation, and controversy remains related to the role of lower respiratory tract colonization with $U u$ and subsequent development of chronic lung injury in the premature infant (28-34).

The majority of human studies have relied on cultures obtained within the first $24 \mathrm{~h}$ of life for correlation with BPD. Of five studies that followed serial cultures, four found an increased risk for BPD among $U u$-colonized premature infants, but nasopharyngeal cultures were sometimes used in place of tracheal cultures to determine colonization $(13,22,23,34,35)$. That $20 \%$ to $40 \%$ of patients may have positive PCRs for $U u$ with negative cultures also confounds efforts to correlate BPD with colonization by $U u(34,36)$. Our study demonstrates that approximately $50 \%$ of immature baboon infants may clear $U u$ from their pulmonary system within the first week after delivery. Infants who fail to clear $U u$ seem to be at increased risk for early lung dysfunction and injury. These findings mirror a recent report on the natural history of $U u$ colonization in human premature infants (37). In that study, $55 \%$ of infants had transient tracheal colonization with $U u$. More important, in- 

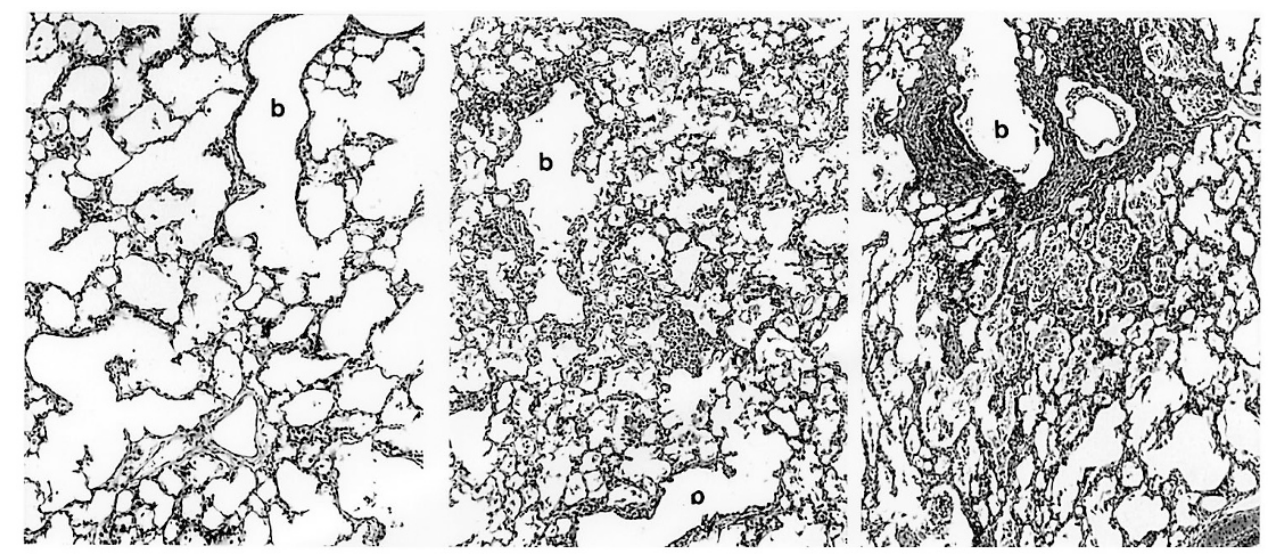

Figure 4. (A) The baseline appearance of an uninfected animal ventilated for $14 \mathrm{~d}$ : very few inflammatory cells in the bronchiolar (b) wall but more obvious interstitial cellularity in the alveolar walls. $(B)$ The lung of a $(-) U u$ animal shows focal bronchiolitis and patchy increased inflammatory cells in the subjacent alveolar walls. $(C)$ The lung from the most severely infected animal shows a dense inflammatory cell infiltrate in the bronchiolar was as well as the intra-alveolar and interstitial compartments. Hematoxylin and eosin; original magnification $\times 40$.
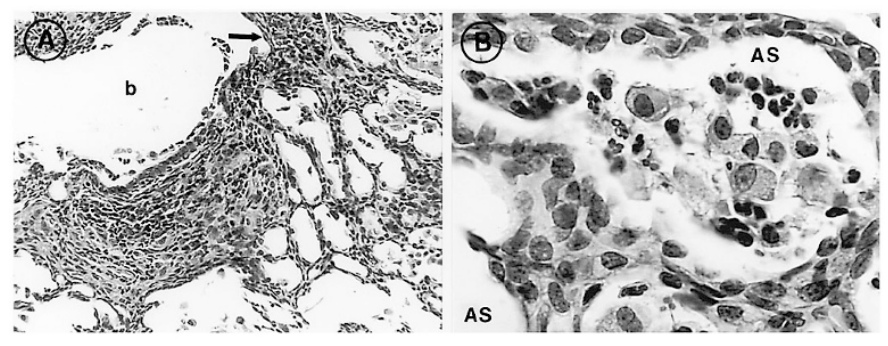

Figure 5. Higher magnification micrographs of the cellular infiltrates in the bronchiolar wall $(A)$ and the distal parenchyma $(B)$ reveal a dominance of mononuclear inflammatory cells and fewer numbers of polymorphonuclear leukocytes. A few inflammatory cells are seen in the bronchiolar lumen (b). The bronchiolar epithelium is denuded focally (arrow). The wall of the bronchiole contains a striking infiltrate of monocytes, some lymphocytes, and polymorphonuclear leukocytes. The subjacent alveolar walls $(B)$ are hypercellular. Focally, an intra-alveolar (AS) exudate of alveolar macrophages, monocytes, and neutrophils is present. Hematoxylin and eosin; original magnification $\times 100(A)$ and $\times 250(B)$.

fants who had persistent tracheal colonization had a significantly increased risk for BPD.

The duration of antenatal exposure in our study was relatively brief and may not be consistent with actual exposure times in the human situation, in which intrauterine colonization may be present for weeks $(38-40)$. However, all animals had similar initial CFUs of $U u$ in amniotic fluid and fetal lung fluid at the time of birth, as well as from TAs at $24 \mathrm{~h}$ of age. In addition, compared with controls, all $U u$-exposed infants had significantly elevated cytokine and white blood cell values in the amniotic fluid and in TAs at birth and $24 \mathrm{~h}$ of age, consistent with an enhanced inflammatory response. Yoon et al. (41) reported similar increases in amniotic fluid cytokines and white blood counts in a group of women with preterm premature rupture of the membranes and positive amniotic fluid cultures for $U u$. We hesitate to conclude on the basis of a single specimen that acute chorioamnionitis, similar to the human condition, consistently occurs in this model.

Several human reports have found in vivo evidence for enhanced pulmonary inflammatory response among premature infants colonized with $U u$ at birth $(7,42-44)$. Groneck et al.
(35) demonstrated that preterm infants who were infected with $U u$ and subsequently developed chronic lung disease exhibited increased tracheobronchial cytokine levels compared with initially colonized infants who did not develop chronic lung disease. As the enhanced inflammatory response was associated with decreased gestational age, the role of immaturityrelated host defense was considered. Given that all of the animals in our study were of similar gestational age, our findings suggest there may be a genetic maturational component to the immune response.

Colonization with a microorganism does not equate to infection. The majority of infants colonized with group B streptococcus do not develop invasive disease. Likewise, many infants may harbor respiratory syncytial virus but not develop significant lower respiratory tract infection. Differences in virulence by serovar subtype, maternal-fetal-neonatal immune system response, and intrinsic pulmonary defense factors, such as surfactant proteins $\mathrm{A}$ and $\mathrm{D}$, may contribute to an individual's risk for infection (45-47). The recent findings by Lofgren et al. (47) that the risk for severe respiratory syncytial virus infection has a genetic association related to specific surfactant protein A alleles point out the importance of variable host intrinsic immune responses at the genetic level.

Women with amniotic fluid colonization by $U u$ have been found to have significantly higher rates of adverse perinatal outcome, including increased preterm birth rates, higher perinatal mortality, and significant neonatal morbidity $(36,48,49)$. It is clear, however, that not all exposed infants have adverse outcomes. In fact, several reports have suggested that chorioamnionitis, especially associated with $U u$, may result in less respiratory distress syndrome and improved survival rates among immature infants $(6,13,50)$. In a series of elegant studies, Jobe and colleagues $(51,52)$ demonstrated that antenatal endotoxin can enhance surfactant production and acutely improve lung function, although this may be at a cost to later lung development. Our finding that one group of $U u$-exposed infants manifested a more benign early course of respiratory distress syndrome is consistent with human reports. Given the two divergent clinical pictures that we encountered, it seems 
that the maternal-fetal-neonatal immunologic response to antenatal $U u$ may play a critical role. That we did not expose control animals to a sham amniocentesis $48 \mathrm{~h}$ before delivery also leaves open the possibility that procedure-related stress may have contributed in a beneficial way to those infants who subsequently cleared the Ureaplasma from their airways (53).

The presented model did not result in maternal or neonatal systemic inflammatory changes as measured by serum cytokine and white blood cell counts. It is unclear whether intraamniotic $U u$ causes a systemic inflammatory response in the human maternal-fetal dyad (54). Although Yoon et al. (41) found a significant increase in fetal cord blood IL-6 values in the presence of amniotic fluid $U u$, they did not report increased maternal serum values. $U u$ is generally considered a weak pathogen except under conditions of immune compromise and may not be capable of generating a systemic inflammatory response in a healthy pregnant woman. As previously noted, the short duration of intrauterine exposure also may not have been long enough to produce a fetal systemic response $(38-40)$.

The pathologic findings in the lung were focal and reflected the findings in only one lobe, the right lower lobe; thus, any disease variability in the entire lung could explain the overlap of the scores. Despite the two significantly different clinical courses, animals from each $U u$-infected group had histologic features that overlapped those of the control animals. Only one animal had intra-alveolar pathology of intermixed neutrophils and alveolar macrophages, a finding that pathologists would readily diagnose as a focal pneumonitis. The interstitial pneumonitis would be more subtle and bothersome to diagnose on biopsy samples because of the tissue compression frequently observed in such samples. It is the composite of findings, a bronchiolitis with subjacent interstitial pneumonitis and increased alveolar macrophages, that characterizes the $U u$ histopathology in this model. This histologic pattern unfortunately is not unique to $U u$-induced lung disease but, if identified in a lung biopsy of a neonate, would suggest that appropriate cultures be done to confirm the diagnosis. Unlike the recent reported finding of moderate to severe fibrosis in autopsy lung specimens of human infants with $U u$ pneumonia, significant fibrosis was not present after $14 \mathrm{~d}$ of ventilation in our animals (55). As ventilator days in the human study ranged from 7 to $45 \mathrm{~d}$, this difference may be due to augmentation of the fibrotic response related to more prolonged mechanical ventilation or to differences in serovar pathogenicity. The lack of elevated IL- 8 values in the bronchoalveolar lavage fluid at the time of necropsy supports the histopathology of $U u$ infection in that intra-alveolar exudates filled with polymorphonuclear leukocytes were not the usual finding in the lung specimens. This pattern is clearly different from what we have observed in other bacterial pneumonias in the baboon in which high levels of IL-8 in bronchoalveolar lavage fluid correlated well with intraalveolar neutrophil-rich exudates (56).

The finding in (-) $U u$ animals of less clinical lung disease than unexposed controls is consistent with the human situation, in which premature infants with minimal lung disease subsequently develop radiographic and clinical features of BPD (13). The presence of prenatal infection induces a premature recruitment of inflammatory cells and surfactant production, both of which may be abnormal when compared with term animals but that could accelerate lung maturation. In the absence of a sustained tracheal $U u$ presence (by culture or PCR) and decreased tracheal cytokine concentrations, it is difficult to explain which factors contributed to histologic pulmonary inflammation in this group. A synergistic effect between hyperoxia and $U u$ has been demonstrated in vivo, and $U u$ induces IL-6 and IL-8 in human neonatal pulmonary fibroblasts even in the absence of hyperoxia $(57,58)$. A wide variety of cytokines and chemokines may play roles in the inflammatory response. Factors other than the limited cytokines that we measured may be involved $(35,42,59)$.

The lack of an acceptable animal model has hampered our ability to better understand any potential role for $U u$ in neonatal chronic lung injury. We have demonstrated that it is possible to produce an intra-amniotic and localized fetal pulmonary inflammatory response in the immature baboon after a relatively brief exposure to $U u$ and that both an acute and a chronic pulmonary response was manifest. Additional studies are needed to determine whether more prolonged exposure can initiate a fetal systemic inflammatory response, to further define factors in the immunologic response that mitigate host colonization, and to broaden the evaluation of other inflammatory mediators/processes. Studies of the effects of $U u$ on other organ systems, most notably the brain, and therapeutic interventions are additional important future goals.

Acknowledgments. We thank all of the personnel who support the BPD Resource Center: the animal husbandry group led by Drs. D. Carey and M. Leland, the NICU staff (H. Martin, S. Ali, D. Correll, R. Degen, S. Gamez, L. Kalisky, and L. Nicley), and the pathology core personnel.

\section{REFERENCES}

1. Pierce M, Bancalari E 1995 The role of inflammation in the pathogenesis of bronchopulmonary dysplasia. Pediatr Pulmonol 19:371-378

2. Ozdemir A, Brown M, Morgan W 1997 Markers and mediators of inflammation in neonatal lung disease. Pediatr Pulmonol 23:292-306

3. Speer C 2001 New insights into the pathogenesis of pulmonary inflammation in preterm infants. Biol Neonate 79:205-209

4. Yoon B, Romero R, Jun K, Park K, Park J, Kim B 1997 Amniotic fluid cytokines (IL-6, TNF- $\alpha$, IL-1 $\beta$, and IL-8) and the risk for development of bronchopulmonary dysplasia. Am J Obstet Gynecol 177:825-830

5. Gonzalez A, Sosenko I, Chandar J, Hummler H, Claure N, Bancalari E 1996 Influence of infection on patent ductus arteriosus and chronic lung disease in premature infants weighing 1000 grams or less. J Pediatr 128:470-478

6. Watterberg K, Demers L, Scott S, Murphy S 1996 Chorioamnionitis and early lung inflammation in infants in whom bronchopulmonary dysplasia develops. Pediatrics 97:210-215

7. Groneck P, Goetze-Speer B, Speer C 1996 Inflammatory bronchopulmonary response of preterm infants with microbial colonization of the airways at birth. Arch Dis Child 74:F51-F55

8. Goldenberg R, Rouse D 1998 Prevention of premature birth. N Engl J Med 339:313320

9. Hillier S, Martius J, Krohn M, Kiviat N, Holmes K, Eschenbach D 1988 A case-control study of chorioamnionic infection and histologic chorioamnionitis in prematurity. N Engl J Med 319:972-978

10. Gibbs R, Romero R, Hillier S, Eschenbach D, Sweet R 1992 A review of premature birth and subclinical infection. Am J Obstet Gynecol 166:1515-1528

11. Romero R, Sirtori M, Oyarun E, Avila C, Mazor M, Callahan R, Sabo V, Athanassiadis A, Hobbins J 1989 Infection and labor. V. Prevalence, microbiology, and clinical significance of intraamniotic infection in women with preterm labor and intact membranes. Am J Obstet Gynecol 161:817-824

12. Cassell G, Waites K, Crouse D, Rudd P, Canupp K, Stagno S, Cutter G 1988 Association of Ureaplasma urealyticum infection of the lower respiratory tract with chronic lung diseases and death in very low birth weight infants. Lancet 2:240-244 
13. Hannaford K, Todd D, Jeffery H, John E, Byth K, Gilbert G 1999 Role of Ureaplasma urealyticum in lung disease of prematurity. Arch Dis Child Fetal Neonatal Ed 81:F162-F167

14. Wang E, Ohlsson A, Kellner J 1995 Association of Ureaplasma urealyticum colonization with chronic lung disease of prematurity: results of a meta-analysis. J Pediatr 127:640-644

15. Walsh W, Butler T, Coalson J, Hensley D, Cassell G, deLemos R 1993 A primate model of Ureaplasma urealyticum infection in the premature infant with hyaline membrane disease. Clin Infect Dis 17(suppl 1):S158-S162

16. Coalson J, Winter V, Siler-Khodr T, Yoder B 1999 Neonatal chronic lung disease in extremely immature baboons. Am J Respir Crit Care Med 160:1333-1346

17. Yoder B, Siler-Khodr T, Winter V, Coalson J 2000 High-frequency oscillatory ventilation. Effects on lung function, mechanics, and cytokines in the immature baboon model of neonatal chronic lung disease. Am J Respir Crit Care Med 162:1867-1876

18. Cassell G, Blanchard A, Duffy L, Crabb D, Waites K 1994 Mycoplasma. In: Howard B, Klass JI, Rubin S, Weissfeld A, Tilton R (eds) Clinical Pathogenic Microbiology. Mosby-Year Book, St. Louis, pp 491-502

19. Blanchard A, Hentschel J, Duffy L, Baldus K, Cassell G 1993 Detection of Ureaplasma urealyticum by polymerase chain reaction in the urogenital tract of adults, in amniotic fluid, and in the respiratory tract of newborns. Clin Infect Dis 17(supp 1):S148-S153

20. Perzigian R, Adams J, Weiner G, Dipietro M, Blythe L, Pierson C, Faix R 1998 Ureaplasma urealyticum and chronic lung disease in very low birth weight infants during the exogenous surfactant era. Pediatr Infect Dis J 17:620-625

21. Wang E, Frayha H, Watts J, Hammerberg O, Chernesky M, Mahony J, Cassell G 1988 Role of Ureaplasma urealyticum and other pathogens in the development of chronic lung disease of prematurity. Pediatr Infect Dis J 7:547-551

22. Payne N, Steinberg S, Ackerman P, Chrenka B, Sane S, Anderson K, Fangman J 1993 New prospective studies of the association of Ureaplasma urealyticum colonization and chronic lung disease. Clin Infect Dis 17(suppl 1):S117-S121

23. Sanchez P, Regan J 1988 Ureaplasma urealyticum colonization and chronic lung disease in low birth weight infants. Pediatr Infect Dis J 7:542-546

24. Pacifico L, Panero A, Roggini M, Rossi N, Bucci G, Chiesa C 1997 Ureaplasma urealyticum and pulmonary outcome in a neonatal intensive care population. Pediatr Infect Dis J 16:579-586

25. Abele-Horn M, Genzel-Boroviczeny O, Uhlig T, Zimmerman A, Peters J, Scholz M 1998 Ureaplasma urealyticum colonization and bronchopulmonary dysplasia: a comparative prospective multicentre study. Eur J Pediatr 157:1004-1011

26. Agarwal P, Rajadurai V, Pradeepkumar V, Tan W 2000 Ureaplasma urealyticum and its association with chronic lung disease in Asian neonates. J Paediatr Child Health $36: 487-490$

27. Galetto Lacour A, Zamora S, Bertrand R, Bright Perret L, Auckenthaler R, Berner M, Suter S 2001 Colonization by Ureaplasma urealyticum and chronic lung disease in premature newborn infants under 32 weeks of gestation. Arch Pediatr 8:39-46

28. Smyth A, Shaw N, Pratt B, Weindling A 1993 Ureaplasma urealyticum and chronic lung disease. Eur J Pediatr 152:931-932

29. van Waarde W, Brus F, Okken A, Kimpen J 1997 Ureaplasma urealyticum colonization, prematurity, and bronchopulmonary dysplasia. Eur Respir J 10:886-890

30. Saxen H, Hakkarainen K, Pohjavuori M, Miettinen A 1993 Chronic lung disease of preterm infants in Finland is not associated with Ureaplasma urealyticum colonization. Acta Paediatr 82:198-201

31. Ollikainen J, Korppi M, Heiskanen-Kosma T, Heinonen K 2001 Chronic lung disease of the newborn is not associated with Ureaplasma urealyticum. Pediatr Pulmono 32:303-307

32. Jonsson B, Karell A-C, Ringertz S, Rylander M, Faxelius G 1994 Neonatal Ureaplasma urealyticum colonization and chronic lung disease. Acta Paediatr 83:927-930

33. Heggie A, Bar-Shain D, Boxerbaum B, Fanaroff A, O'Riordan M, Robertson J 2001 Identification and quantification of ureaplasmas colonizing the respiratory tract and assessment of their role in the development of chronic lung disease in preterm infants. Pediatr Infect Dis J 20:854-859

34. Da Silva O, Gregson D, Hammerberg O 1997 Role of Ureaplasma urealyticum and Chlamydia trachomatis in development of bronchopulmonary dysplasia in very low birth weight infants. Pediatr Infect Dis J 16:364-369

35. Groneck P, Schmale J, Soditt V, Stutzer H, Gotze-Speer B, Speer C 2001 Bronchoalveolar inflammation following airway infection in preterm infants with chronic lung disease. Pediatr Pulmonol 31:331-338

36. Yoon B, Romero R, Kim E, Kim T, Park J, Jun J 2000 Clinical implications of detection of Ureaplasma urealyticum in the amniotic cavity with the polymerase chain reaction. Am J Obstet Gynecol 183:1130-1137
37. Castro-Alcaraz S, Greenberg E, Bateman D, Regan J 2002 Patterns of colonization with Ureaplasma urealyticum during neonatal intensive care unit hospitalizations of very low birth weight infants and the development of chronic lung disease. Pediatrics 110(4). Available at: pediatrics.aappublications.org/cgi/content/full/110/4/e45

38. Berg T, Philpot K, Welsh M, Sange W, Smith C 1999 Ureaplasma/Mycoplasmainfected amniotic fluid: pregnancy outcome in treated and nontreated patients. J Perinatol 19:275-277

39. Bashiri A, Horowitz S, Huleihel M, Hackmon R, Dukler D, Mazor M 1999 Elevated concentrations of interleukin-6 in intra-amniotic infection with Ureaplasma urealyticum in asymptomatic women during genetic amniocentesis. Acta Obstet Gynecol Scand 78:379-382

40. Horowitz S, Mazor M, Horowitz J, Porath A, Glezerman M 1995 Antibodies to Ureaplasma urealyticum in women with intraamniotic infection and adverse pregnancy outcome. Acta Obstet Gynecol Scand 74:132-136

41. Yoon B, Romero R, Park J, Chang J, Kim Y, Kim J, Kim K 1998 Microbial invasion of the amniotic cavity with Ureaplasma urealyticum is associated with a robust host defense in fetal, amniotic, and maternal compartments. Am J Obstet Gynecol 179:1254-1260

42. Patterson A, Taciak V, Lovchik J, Fox R, Campbell A, Viscardi R 1998 Ureaplasma urealyticum respiratory tract colonization is associated with an increase in interleukin 1-beta and tumor necrosis factor alpha relative to interleukin 6 in tracheal aspirates of preterm infants. Pediatr Infect Dis J 17:321-328

43. Panero A, Pacifico L, Rossi N, Roggini M, Chiesa C 1995 Ureaplasma urealyticum as a cause of pneumonia in preterm infants: analysis of the white cell response. Arch Dis Child 73:37-40

44. Baier R, Loggins J, Kruger T 2001 Monocyte chemoattractant protein-1 and interleukin-8 are increased in bronchopulmonary dysplasia: relation to isolation of Ureaplasma urealyticum. J Investig Med 49:362-369

45. Quinn P, Li H, Dunn M, Butany J 1993 Serological response to Ureaplasma urealyticum in the neonate. Clin Infect Dis 17(suppl 1):S136-S143

46. Talati A, Crouse D, English B, Newman C, Livingston L, Meals E 1998 Exogenous bovine surfactant suppresses tumor necrosis factor-alpha release by murine macrophages stimulated by genital mycoplasmas. J Infect Dis 178:1122-1125

47. Lofgren J, Ramet M, Renko M, Marttila R, Hallman M 2002 Association between surfactant protein A gene locus and severe respiratory syncytial virus infection in infants. J Infect Dis 185:283-289

48. Yoon B, Chang J, Romero R 1998 Isolation of Ureaplasma urealyticum from the amniotic cavity and adverse outcome in preterm labor. Obstet Gynecol 92:77-82

49. Romero R, Chaiworapongsa T 2002 Preterm labor, intrauterine infection, and the fetal inflammatory response syndrome. Neoreviews 3:e73-e84

50. Costeloe K, Hennessy E, Gibson A, Marlow N, Wilkinson A 2000 The EPICure study outcomes to discharge from hospital for infants born at the threshold of viability. Pediatrics 106:659-671

51. Moss T, Newnham J, Willett K, Kramer B, Jobe A, Ikegami M 2002 Early gestational intra-amniotic endotoxin: lung function, surfactant and morphometry. Am J Respir Crit Care Med 165:805-811

52. Jobe A, Newnham J, Willet K, Sly P, Ervin M, Bachurski C, Possmayer F, Hallman M, Ikegami M 2000 Effects of antenatal endotoxin and glucocorticoids on the lungs of preterm lambs. Am J Obstet Gynecol 182:401-408

53. Tabor B, Lewis J, Ikegami M, Polk D, Jobe A 1994 Corticosteroids and fetal intervention interact to alter lung maturation in preterm lambs. Pediatr Res 35:479483

54. Gomez R, Romero R, Ghezzi F, Yoon B, Mazor M, Berry S 1998 The fetal inflammatory syndrome. Am J Obstet Gynecol 179:194-202

55. Viscardi R, Manimtim W, Sun C, Duffy L, Cassell G 2002 Lung pathology in premature infants with Ureaplasma urealyticum infection. Pediatr Dev Pathol 5:141150

56. Awasthi S, Coalson J, Yoder B, Crouch E, King R 2001 Deficiencies in lung surfactant proteins $\mathrm{A}$ and $\mathrm{D}$ are associated with lung infection in very premature neonatal baboons. Am J Respir Crit Care Med 163:389-397

57. Crouse D, English B, Livingston L, Meals E 1998 Genital mycoplasmas stimulate tumor necrosis factor-alpha and inducible nitric oxide synthase production from a murine macrophage cell line. Pediatr Res 44:785-790

58. Stancombe B, Walsh W, Derdak S, Dixon P, Hensley D 1993 Induction of human neonatal pulmonary fibroblast cytokines by hyperoxia and Ureaplasma urealyticum. Clin Infect Dis 17(suppl 1):S154-S157

59. Manimtim W, Hasday J, Hester L, Fairchild K, Lovchik J, Viscardia R 2001 Ureaplasma urealyticum modulates endotoxin-induced cytokine release by human monocytes derived from preterm and term newborns and adults. Infect Immun 69:3906-3915 